\title{
28 Years of Walking the Global Streets and a Challenge: ISTEC 1990-2018
}

\author{
Ramiro Jordan \\ School of Engineering - ISTEC \\ University of New Mexico \\ Albuquerque, NM, USA \\ rjordan@unm.edu,rjordan@istec.org \\ Paulo Franco \\ PUCRS \\ Porto Alegre, Brazil \\ paulogfranco@gmail.coml
}

\author{
Marisa de Giusti \\ Directora Liblink - ISTEC \\ Universidad Nacional de La Plata \\ La Plata, Argentina \\ mdegiusti@gmail.co
}

\author{
Donna Koechner \\ eNOVA Solutions \\ Albuquerque, NM, USA \\ dmkoechne@usa.net
}

\author{
Kamil Agi \\ SensorComm Technologies, CEO \\ Albuquerque, NM, USA \\ kagi@sensorcommtech.com
}

\begin{abstract}
The intent is to share 28 years of experience of the Ibero-American Science and Technology Education Consortium (ISTEC, www.istec.org). The original idea of ISTEC was to use Science and Technology (S\&T) as the common language and catalyst for social, cultural, political, and economic development. We envisioned then the use of S\&T language for practical Peace Engineering international efforts. ISTEC is also about sharing (information, technology, services) by forming alliances among academia, industry, government agencies, and multilateral organizations. The success of ISTEC is based in Trust, that is: transparency, efficiency, effectiveness, professionalism, competitiveness, competence, knowledge, culture of quality and accountability. ISTEC is action oriented. We intend to share the problems we encountered and identified, the initiatives developed to tackle those problems, our successes and failures, our experience from managing the organization to project development and execution of the different initiatives. Lastly, we want to establish a dialogue under Peace Engineering to address the current and future Global Challenges. Therefore, the specific challenge is for IFEES-GEDC leadership and its membership to create a Peace Engineering Initiative under which concrete efforts can be identified, developed, funded and executed.
\end{abstract}

Keywords: internationalization, Peace Engineering, diversity, challenge, common language.

\section{INTRODUCTION}

ISTEC, created in 1990, is the result of an Engineering Education research effort led by Dr. Ramiro Jordan at the University of New Mexico (UNM) and sponsored by Motorola, Inc. The premises were: 1) can the language of Science and
Technology (S\&T) be used to facilitate collaboration among different types of institutions including academia, industry and governments; 2) can S\&T be used to integrate the region of Latin America and the Caribbean in local, national and global contexts; 3) is Science and Technology part, or should it be included, in the socio-economic development plans for countries in Ibero-America.

In June of 1999, ISTEC became a U.S. 501c3 non-profit corporation comprised of academic, research, industrial, and multilateral organizations throughout the Americas and the Iberian Peninsula ISTEC has proven to be a highly successful and impactful spinoff from UNM [1].

\section{THE IMPETUS}

In 1990 personnel from the University of New Mexico visited countries in Latin America to identify and evaluate opportunities for successful collaboration in science, technology and education. Meetings were held with officials from governments, educational institutions, research facilities, and industrial firms to gauge interest in establishing efforts for international cooperation in technical fields. The meetings resulted in the identification of areas of common interest for employing hands-on experiential and project-based education, research, and technology transfer in state-of-the-art technology and science. Following the visits, an organizational meeting was held in December of 1990 at the University of New Mexico involving personnel from universities, industries, governments, and foundations throughout Ibero-America. Several obstacles 
were identified from the fact-finding mission that needed to be addressed immediately. They included:

- Lack of current information for planning and developing technology

- Lack of expertise in the use of information

- Lack of international cooperation in developing the critical mass needed for projects and joint efforts

- Lack of interaction and confidence among universities, industries, governments, and multilateral agencies

- Lack of the availability of technology

- Lack of entrepreneurial skills to bring technology and intellectual property to the marketplace

The above difficulties were aggravated by a lack of awareness of the simultaneous existence of, and interaction between, these obstacles. It was imperative that efforts be made to address these issues concurrently to further the scientific and technological development of Ibero-America. It was the consensus among the participants in the meeting that traditional mechanisms for cooperation were not sufficient, and new, more effective mechanisms were needed $[2,3]$. These discussions led to the creation of the Ibero-American Science and Technology Education Consortium (ISTEC).

\section{THE BIRTH OF ISTEC}

To understand the context when ISTEC was created, let's look back to 1990. The Internet was in its infancy. Not even multi-lateral organizations such as World Bank, Inter-American Development Bank and the Organization of American States were aware of the potential of the Internet. Information and Communications Technology (ICT) was not included in the socio-economic development plans of most countries. Hardly any of the countries in the region invested in S\&T. Many countries were coming out of authoritarian regimes, and some had internal armed struggles. Collaboration efforts among academia-industry-governments locally and in an international context was near zero. Mobility of students and faculty was scarce. Accreditation efforts to assess the quality of education in academia were almost non-existent. Access to information and the latest technology was only available to wealthy institutions, and very limited to specific areas (both technical and geographical). Ranking of academic institutions was not well understood. Private academic institutions were few, thus there was little competition to drive academic excellence. Import tariffs for academic teaching and research laboratories were prohibitive. There was no Open Access movement to facilitate software and digital content exchange. There was little integration of the countries as a region to have a voice in the global context. (even today this is true). There were many other impediments, the majority self-imposed by local governments.

It is in this context that UNM faculty started a movement by attracting US and Ibero-American academic and industrial institutions, R\&D laboratories, multilateral organizations and governments to collaborate. The people identified in these organizations had the passion to escalate the advancement of Science and Technology in Ibero-America and were catalysts of change. The idea was to integrate the region and enhance socioeconomic development by using a common language, the language of Science and Technology. ISTEC's founding members created the organization under the following charter:

Vision: ISTEC will be a leading organization to improve the quality of life in Ibero-America

Mission: to foster socio-economic development in IberoAmerica by carrying out programs focused on:

- Advancing the state of education, and promote the culture of quality,

- Generating and disseminating knowledge and information,

- Establishing cost-effective vehicles for technology transfer,

- Encouraging joint international research and development,

- Creating an environment for entrepreneurship.

All of this, while nurturing a network that promotes trust and integration between academia, government, industry and civil society; we also strive to strengthen social responsibility as a common shared value in the Region.

\section{A. Organizational Structure}

For the organization to be sustainable, ISTEC's founders followed the membership model, requiring an annual fee from all members of the consortium. For industrial institutions a three-level membership was instituted with varying benefits. For academic institutions the membership was the same independent of the nationality or "size" of the institution. The funds generated by the membership allowed for the Executive Office to function, managing the Consortium, securing resources (money, donations in kind), and helping members identify resources write proposals, and promote and market their institutions and projects.

The success of ISTEC is based on Trust: transparency, efficiency, effectiveness, professionalism, competitiveness, competence, knowledge, culture of quality and accountability. ISTEC is an action-oriented organization comprised of:

- A General Assembly (GA) to which all members belong, and which sets policy and direction;

- A Board of Directors made up of academic and industrial members of the General Assembly, and which implements policies and promotes the Consortium, and

- An Executive Office that handles the day-to-day operations of the organization.

ISTEC participants encourage the free flow and access of information in the pursuit of technical excellence.

\section{B. Initiatives}

The Consortium identified a series of Objectives to conceive, plan, and carry out activities of higher education, research and development, and technology transfer to facilitate the scientific and technical progress of Ibero-American countries. ISTEC created Initiatives as a mechanism to address these Objectives.

An Initiative is an organized effort to create activities to address a specific area of concern The Initiative mechanism 
enables ISTEC to work on its objectives by involving personnel and resources from diverse geographical locations. The Initiative concept provides an effective way to address to the challenges present in Ibero-America. They are member-driven, flexible, and run concurrently. Within initiatives, projects are identified, planned, and implemented. The distributed structure from which the projects stem avoids duplication of efforts and inherently responds to the needs of the ISTEC membership. Projects are designed with both short- and long-term goals, as well as consideration of social impact. They are dynamic and expandable, and coordination is required to maximize the utilization of available resources. Currently, there are four Initiatives underway: Library Linkages, Advanced Continuing Education, Research and Development Laboratories, and Los Libertadores (entrepreneurship, innovation and leadership) [4].

\section{The Importance of Connectivity}

At the beginning maintaining the interest of all partners was very difficult because there was no Internet and phone calls were extremely expensive, so regular mail was the main communications mechanism. ISTEC's conviction and passion that using the language of S\&T to collaborate and integrate the Region was critical.

ISTEC focused on educating academic authorities, faculty, staff and students on the importance of the Internet, that is, connectivity. Once there is connectivity then comes the ability to access information like digital libraries. Connectivity also solves the problems of training the trainer with best practices in teaching, content development, on-line education and remote labs and classrooms. With connectivity, we planted the idea of "the culture of quality", encouraging evaluation and accreditation of educational programs, high quality research and publications, entrepreneurship and tech transfer. ISTEC also used its expertise to influence government officials to integrate ICT into their socio-economic development plans.

\section{Evolution}

Slowly but surely, we began connecting libraries and sharing information. Equipment donations from industry started to flow for teaching and research laboratories. Academic content began to be exchanged; an on-line platform was developed for academic members to share content. High-performance computing centers and centers of excellence began to be discussed. We installed the first Cray Research super-computing center in Latin America at UNAM in 1991. Multidimensional signal processing and visualization laboratories, created using the Khoros software development environment, were being replicated from UNM and distributed throughout IberoAmerica. Similar laboratories sponsored by Nortel and Motorola were replicated from UNM and established at ISTEC academic member institutions. The CEITEC (Center of Excellence for Semiconductor Industry) was created and TECNOPUC technology park followed. ICT Challenges were organized throughout the Latin American and Caribbean Region with the support of Motorola to inform and educate academic, government and local industry leaders of the importance of ICT for their socio-economic development plans. The InterAmerican Development Bank also participated in various ICT events. With the Corporación Andina de Fomento (CAF) we organized one of the first Latin American business plan competitions in Campinas, Brazil, at UNICAMP.

In the late 1990s, the fact that institutions were paying membership fees through UNM to participate in the ISTEC program became a concern. To solve money flow issues and to ensure a clear and transparent organization with its own management team, ISTEC spun off from UNM to form a 501c3 non-for-profit organization (June 1, 1999). The organization maintained the same governing structure and charter but is independent of any other institution or entity.

\section{Peace Engineering in ACtion}

The common language of S\&T is neutral to political color. In the context of Peace Engineering and collaboration, ISTEC has been an early adopter and a catalyst for nearly three decades.

ISTEC has promoted strategic alliances between Academia, Industry, and Government to incite social, cultural, political and economic development. ISTEC is a unique organization where academia, industry and governments work together, we think one of its kind for Ibero-America. What follows are some statistics on what ISTEC has achieved in the last 28 years:

i) OAS Collaborations: In 18 years of collaboration with the OAS, thousands of scientist and engineers trained in the areas of Digital Signal and Image Processing; over 1000 software development and research laboratories implemented using KHOROS; developed the Educational Portal of the OAS.

ii) Open Access: Actively participated in the creation of the Open Access community. Held the Santa Fe Alliance conference in 1999 where the business model with publishers changed worldwide to include consortia purchasing and open access. In 2002, ISTEC signed as a founding member of the Open Access movement that prevails today. The annual BIREDIAL-ISTEC International Conference is one of the. most important events where Open Access issues are addressed by global experts.

iii) Indexed International Technical Journals: Created Journal of Computer Science and Technology (http://journal.info.unlp.edu.ar/) and Revista Iberoamericana de Tecnologia en Educacion y Educacion en Tecnologia (http://teyet-revista.info.unlp.edu.ar), which are both highly active and growing.

iv) Student Contests: Student Design contests were held during ISTEC General Assembly events. Finalist were invited to attend the General Assembly and prizes awarded to top three contestants.

v) International Graduate Programs: Double graduate degree, 4+1 (4 years undergraduate and 1 year graduate), and Entrepreneurship and Technology Management programs were established and to foster and raise the quality of research in the region and to promote mobility.

vi) Centers of Excellence: ISTEC helped create the Center de Excellence in Digital Content at the Universidad de Monterrey; in 2000 participated with Motorola in the 
creation of CEITEC (Center of Excellence for Semiconductor Industry): Porto Alegre, Brazil.

vii) Economic Development: Partnered with UNM to create an Economic Development center "La Plazita" in the South Valley of Albuquerque to help low-income families in troubled areas.

viii) Strategic Alliances: Over 100 active university members in the IEEE Latin American and Iberian Peninsula Regions; multilateral organizations and professional societies including: Organization of Americas States - Engineering for the Americas (OAS-EftA), American Society for Engineering Education (ASEE), Institute of Electrical and Electronics Engineers (IEEE), Banco de Desarrollo de América Latina (CAF), Interamerican Development Bank (IADB), United Nations Educational, Scientific and Cultural Organization (UNESCO), Latin American Technological Information Network (RITLA),

ix) Engineering for the Americas (EftA): Co-Founder and member of the Advisory Board of EftA. EftA is an Initiative at the level of all Heads of State of the Region that proposes a change of paradigm, wherein engineering provides a basis for broad, sustainable improvements throughout the Americas. Engineers, whose degrees are based on international standards of quality, are critical to provide an essential skilled workforce to compete with Asia, India, and the European Union. By seeking to improve engineering education and apply quality assurance, mobility of both work and workflow can open new doors, drive organic creativity, create jobs and foster economic and social growth.

x) Accreditation and Culture of Quality: Designed and developed the GRANA software platform to offer academic institutions an opportunity to develop a strategic plan leading them to an international evaluation, and then accreditation, of academic programs. The platform also has content to train individuals in becoming evaluators. Over 100 institutions in Latin America have been evaluated and over 500 evaluators trained.

xi) Growing with Technology Award: CISCO Systems awarded ISTEC the 2004 Growing with Technology Award in recognition of Innovative Companies that Are Networked for Growth.

xii)Partnerships with Industry: Helped create Global Innovation Network for Entrepreneurship and Technology (GINET LLC) and Corcel/Steed Ventures LLC (Partner and founder).

xiii) IFEES: ISTEC is a founding member of International Federation of Engineering Education Societies IFEES, 2006-Present.

xiv) ICT Infrastructure: Installed the first Cray Research Supercomputer in Latin America at UNAM in 1991; developed regional information networks in Brazil, Bolivia, Colombia, Mexico, Ecuador, Venezuela, Uruguay, Costa Rica and Argentina. xv) Information Technology Challenges: Sponsored and funded over 10 ICT Challenge forums to create awareness, analyze existing ICT models and develop an ICT regional agenda.

xvi) Learning Aids: Developed hands-on laboratory manual in Software Design Radios (5G) in partnership with National Instruments; as well as first IEEE ComSoc hands-on manual. In partnership with Quanser, developed mobile APPS for experiential learning and R\&D using the QDEX environment, being the first in mobile content development for engineering education.

xvii)Policy Advisement: helped developed the new S\&T legislature of Brazil. Advised United Nations Latin America ambassadors in S\&T to incorporate ICT in the Charter of the Economic and Social Council.

xviii) Knowledge Sharing: Over 70 academic libraries sharing information in real time within the ISTEC Digital Library Linkage Initiative; On average 15,000 documents are transferred annually within the DLL network, saving region hundreds of thousands of dollars annually.

xix) Laboratories: Established over $500 \mathrm{R} \& D$ labs in 17 countries (mostly in digital signal processing, communications, software development, microcontrollers, and embedded systems). We have lost track of the number of students trained in the past 20 years. It is well over 300,000 .

xx) Equipment \& Software Donations: Secured over $\$ 10$ million in equipment and software donations from Motorola, Quanser, Hewlett Packard, Nortel Networks, Microsoft, Sun Microsystems, National Instruments, Cisco, Xilinx, and Intel for development of S\&T in the region. (As an example, Intel donated a $\$ 1.5 \mathrm{M}$ scanning electron microscope to TECNOPUC.)

xxi) Intellectual Property: Secured an IP license from Motorola to design chips with their MCORE technology. Each license is worth in the hundred thousand dollars and was given free to ISTEC members. Synopsis and Mentor Graphics joined this effort to allow Latin American universities to design new generation chips with their tools. Silterra agreed to fabricate educational/research chips in partnership with CEITEC.

xxii) Experiential Learning for S\&T: The Innovation Plaza and WHY lab environments are hands-on spaces with global connectivity formulated to enrich hands-on engineering curricula, foster a scientific approach, collaboration and facilitate mobility. These labs are introduced in the students' first years to help bridge the gap connecting Math, Physics and Chemistry to Engineering at a very early stage by linking theory to real world experience. This improves retention and graduation rates and fosters entrepreneurship. Students discover their engineering vocation based on representative engineering applications. Both labs use current industry tools, which makes the engineering degree more relevant and marketable. 


\section{ISTEC LOOKING FORWARD}

In 1990 ISTEC was one of the first consortiums to bring academia-industry-governments to play in the realm of Science and Technology. Since its inception many other organizations have been created; many of them replicating ISTEC's mission and vision in some form or shape. By 2006 the global competition of similar organizations exploded, and resources started shrinking.

It is easy for organizations like ISTEC to be viewed as charities through the eyes of academic organizations in the developing world - viewed as a resource that they can draw upon but to which they do not need to contribute. ISTEC is a consortium where all members contribute and actively participate to enhance not only member organizations, but the region and the consortium itself. A professional forward-looking Board of Directors and Management team is key to the success of an organization of this nature. There are many leaders but few champions. And champions are what organizations like ISTEC need. A champion does what? Where do we find them?

In 28 years, we have had our share of good, bad and ugly experiences, but most have been extremely productive and rewarding and we are very proud of the impact that the Consortium and its members have made in the Ibero-American Region. ISTEC is an action-oriented organization - we execute projects to make a difference including laboratory facilities, online content, digital libraries, etc.

The obstacles we identified in 1990 are still a reality in much of the world. Additionally, we need to address the impact of the new socio-economic models like Industry 4.0/5.0, the Circular Economy $[5,6]$. Thus, the concept, mission and vision of ISTEC are still valid.

The authors believe that ISTEC can be replicated, for instance, we would like to create the African Science and Technology Education Consortium (ASTEC).

ISTEC wants to collaborate with like-minded, action oriented organizations, such as Engineers Without Borders, to achieve the best possible outcomes for our world.

Since its inception, the mission of ISTEC has always been "to be a leading organization to improve the quality of life". ISTEC is, and has always been, committed to Peace Engineering.

\section{A CHALLENGE FOR IFEES AND GEDC}

In 2006 ISTEC became a founding member of the International Federation of Engineering Education Societies (IFEES). There was a great need then, and an even greater need now, to establish a forum where all engineering organizations can exchange best practices, share information, look at trends and needs globally, work to improve engineering education globally, identify research opportunities, foster entrepreneurship (business and social), empower student organizations, identify resources, address global challenges, and have a stronger voice in society.
The authors believe that in order to make a difference worldwide and have fun doing it, action-oriented efforts are essential. Our challenge to IFEES and GEDC is to come up with concrete, measurable, efforts that can be designed, executed, measured and reported. By targeting the development on key best practices, measuring the outcomes and focusing on impact, the world can be made into a better place through the language of science and technology.

In addition, awards should be created to incentivize activities globally. We strongly believe in the Peace Engineering movement. Many academic institutions have created programs and more need to be created worldwide - all acting in concert to address the global challenges identified by NAE and the United Nations $[5,6]$. We need to educate the next generation of global engineers.

\section{ACKNOWLEDGMENTS}

The authors would like to thank ISTEC, UNM, UNLP, PUCRS, eNOVA Solutions and SensorComm Technologies for the fruitful discussions in developing the concepts presented.

\section{REFERENCES}

[1] Jordan, R., "¿What is the Ibero American Science and Technology Education Consortium- ISTEC?," Políticas Públicas y Carreras de Ingeniería. Lecture conducted from XXXVII Reunión Comité Ejecutivo ASIBEI, Ushuaia, Argentina, November 2015.

[2] Jordan, R., "Innovation Plaza: Experiences and best practices in sharing hand-on education materials globally," Global Engineering Education. Lecture conducted from XXXVII Sixth International Conference on Industrial Engineering and Operations Management (IEOM), Kuala Lumpur, Malaysia, March 2016a.

[3] Jordan, R., "Experiencias innovadoras en Facultades de Ingeniería. Innovación en Facultades de Ingeniería," Lecture conducted from Global Engineering Deans GEDC-LATAM, Cartagena, Colombia, October 2016 b.

[4] Jordan, R., "The Global University to the challenges of local development: the role of internationalization of higher education. Hacia una política de internacionalización de la educación superior de impacto: vinculación global, calidad, pertinencia y competitividad," Lecture conducted from 8th Latin American and Caribbean Higher Education Conference- LACHEC, Bogotá, Colombia, November 2016c.

[5] National Academy of Engineering. (2004). 4 Attributes of Engineers in 2020. The Engineer of 2020: Visions of Engineering in the New Century. Washington, DC: The National Academies Press. doi: 10.17226/10999.

[6] United Nations Educational, Scientific and Cultural OrganizationUNESCO, Intercultural Competences, France, 2013 